ESRC Centre for Analysis of Risk and Regulation

Incentives, Choice and Accountability in the Provision of Public Services

Timothy Besley and Maitreesh Ghatak 


\section{Incentives, Choice and Accountability \\ in the Provision of Public Services}

Timothy Besley and Maitreesh Ghatak

\section{Contents}

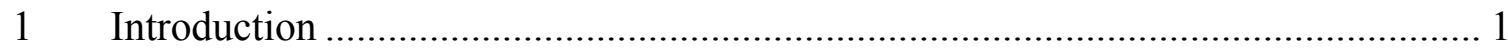

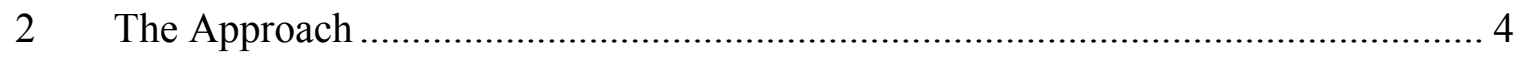

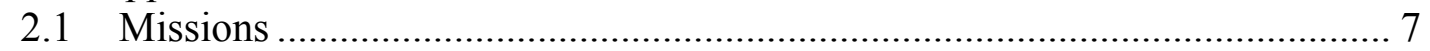

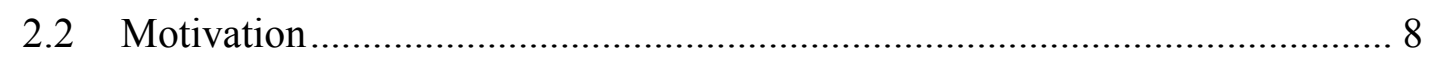

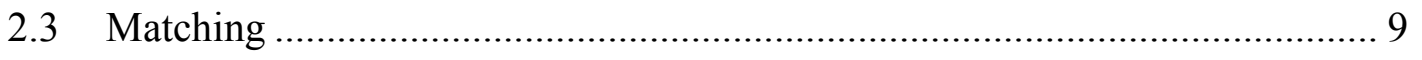

3 Three Models of Public Service Provision ............................................................ 9

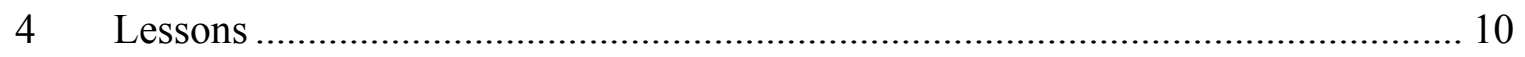

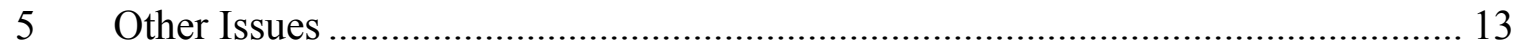

5.1 Costs of Choice and Competition ............................................................... 13

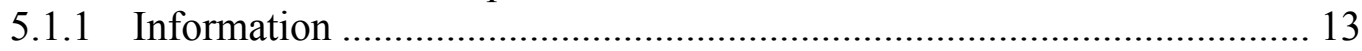

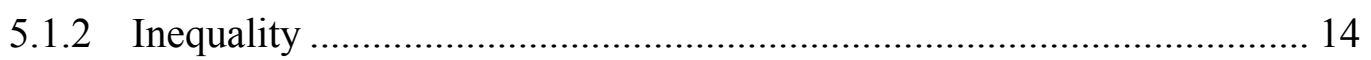

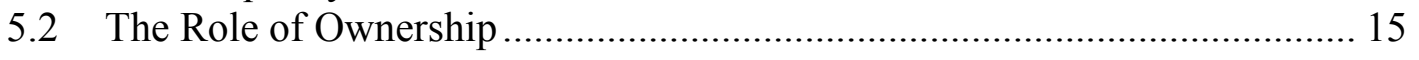

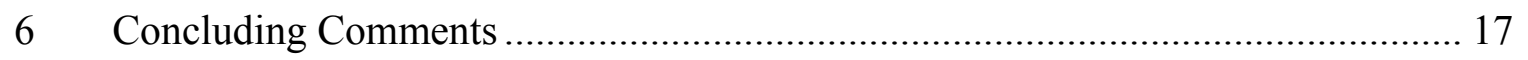


The support of the Economic and Social Research Council (ESRC) is gratefully acknowledged. The work was part of the programme of the ESRC Centre for Analysis of Risk and Regulation.

Published by the Centre for Analysis of Risk and Regulation at the London School of Economics and Political Science

Houghton Street

London WC2A $2 \mathrm{AE}$

(C) London School of Economics and Political Science, 2003

ISBN 0753016508

All rights reserved.

No part of this publication may be reproduced, stored in a retrieval system, or transmitted, in any form or by any means, without the prior permission in writing of the publisher, nor be otherwise circulated in any form of binding or cover other than that in which it is published and without a similar condition including this condition being imposed on the subsequent purchaser.

Printed and bound by Printflow, June 2003. 


\title{
Incentives, Choice and Accountability in the Provision of Public Services
}

\author{
Timothy Besley and Maitreesh Ghatak*
}

\begin{abstract}
This paper discusses a theoretical framework to study the issues of competition and incentives without relying on the standard profit-orientated "market" model in the context of the debates about public service reform in the UK. It uses the idea that the production of public services coheres around a mission, and discusses how decentralised service provision can raise productivity by matching motivated workers to their preferred missions. Our focus on competition and incentives cuts across traditional debates about public versus private ownership and allows for the possibility of involving private non-profits. We also address concerns about the consequences of allowing more flexibility in mission design and competition on inequality.
\end{abstract}

\section{Introduction}

Reforming public service delivery occupies a central position in the current policy agenda both in the UK and elsewhere in the world. However, no clear theoretical framework, has yet emerged for the study of these problems. ${ }^{1}$ A key issue is whether problems of public service delivery are qualitatively different from manufacturing state-of-the-art motor vehicles or running a good travel agency. If there is nothing especially different, then we can draw on the vast knowledge-base available for studying the private sector to discuss issues in public service delivery. ${ }^{2}$ Many discussions proceed as if the agenda is exactly that - to merge the distinction between the public and private. To that end, two features of private market activity have caught the attention of would-be reformers - the role of choice and competition, and the use of incentives.

The role of this paper is to discuss some aspects of competition and incentive design which are relevant to ongoing policy debates in the UK and elsewhere. The paper accepts the basic premise that it is important to blur the traditional distinction between public and private sectors. However, to that end, a key issue is to change how the

\footnotetext{
* The authors are grateful to Tony Atkinson, Paul Grout, Howard Glennerster, Elisabetta Iossa, Steve Nickell, Carol Propper, and Margaret Stevens for helpful comments.

1 It is striking that the public economics literature of 20 years ago (as summarised in Atkinson and Stiglitz, 1980) paid almost no attention to incentive problems in public production.

${ }^{2}$ See Nickell (1995) for an excellent overview of factors governing private sector performance.
} 
term "public" is to be understood when referring to public services. It is confusing, to equate "public" with public ownership. The government might undertake the production of, say, automobiles. In a literal sense it would then be part of the public sector. However, the optimal organisation design issues here would be no different than those faced by GM or Ford.

Instead, we suggest that the term public reflects the fact that these are services produced for the benefit of the public at large, ie, goods whose consumption yields collective benefits. Thus, public services are goods that an unregulated market will tend to under-provide. There are three well-known reasons:

- External benefits - societies with healthier and better educated populations benefit everybody, not just those whose health or education is at stake. This could be because we care about others, or, more instrumentally, because better education reduces crime or dependence on the state or raises the quality of public discourse.

- Egalitarianism - the hallmark of any civilised society is to deliver some minimum levels of consumption of key goods (such as healthcare or housing) to its population.

- $\quad$ Merit Goods - individuals may not understand or appreciate the benefits that can result from consumption of goods such as education and health services. This could be due to information problems, or because of the failure of rational forward-looking decision-making typically assumed in economics. Also, agency problems could arise if parents do not value the education of their children sufficiently.

Markets fail in these contexts because price signals do not adequately reflect the social value of consumption. The existence of these concerns lead to solutions for provision of public services that attenuate the use of the profit-motive, which is the driving force behind market provision. However, there is much debate about the precise form that these alternative models of provision should take.

The traditional model in the UK has been centralised government provision with an attempt to achieve a fairly uniform system of provision across the country as a whole, with the major initiatives dictated by the centre. But this has increasingly come under fire in recent times. The main criticisms are:

- $\quad$ Absence of choice - individuals needs and preferences differ (eg, concerning the importance of preventive care in the health context or importance of extracurricular activities in schools), but public services tend to focus on one-sizefits-all provision.

- Inefficiency in production - providers of services face limited incentives to improve service quality of service since service-users are not viewed as "customers" as in the private sector, whose satisfaction is key to their own survival. Also, they have no incentives to cut costs because of the operation of soft budget constraints. 
The current reforms are part of an effort that started in the Thatcher years which have increasingly tried to move away from this model, creating greater scope for diversity and local initiatives. However, those advocating borrowing ideas from the private sector and introducing elements of choice, incentives and competition, sometimes tend to forget that these goods and services are fundamentally different from standard private goods and so what works in the private sector may not necessarily work here. Moreover, putting power in the hands of the patient or parent, or giving incentives to a hospital manager to cut costs, means that these spheres, too, may be dominated by the inequalities in private resources.

On the other hand, as evidenced in the recent debate on Foundation Hospitals in the UK, traditionalists who resist reform tend to under-emphasise the costs of centralised public provision, with the implicit belief being that the gains in terms of equality of the present system are far more important compared to the losses in terms of efficiency. Moreover, there is considerable evidence that even under this model, service provision remains inequitable with too many failing schools and hospitals being located in areas with greatest deprivation, with resources being diverted to those who are best able to manipulate the system, namely the educated and articulate middle classes (see LeGrand, 1991 and the references cited there). Therefore, it seems important to explore the possibility of reforms that create win-win situations where gains from efficiency do not necessarily come at the expense of equality.

These debates would benefit from having a conceptual framework to study competition and incentives which does not rely on the standard profit-orientated model of production. There is a long-standing role in the UK and elsewhere for the "third" sector - non-governmental organisations that produce goods and services, but do not do so for profit. ${ }^{3}$ There is also an extensive literature in economics on the notfor-profit sector (see, for example, Weisbrod, 1988).

However, there is little unity between this literature and the literature on the public sector. This gives the impression that public and private ownership are such fundamentally different things that these organisations have little in common. While we do not wish to under-emphasise the importance of ownership (see the discussion in Section 5.2) we would like to argue that these organisations share similar organisation-design concerns relating to the structure of accountability, incentives, and the extent of competition for service-users as well as personnel. ${ }^{4}$

This paper suggests an approach to public organisations that tries to unify the disparate discussions of the role of private non-profit activity and public bureaucracies. It builds on the unifying theme that not-for-profit activity and public sector bureaucracies are organisations that try to cohere around a mission. The notion of a mission replaces the conventional focus on profit. We argue that people work harder when they buy into the mission of the organisation and this raises productivity. For a more formal treatment of these issues, see Besley and Ghatak (2003).

\footnotetext{
3 See, for example, Billis and Glennerster, 1998.

4 The role of the third sector in the UK is frequently discussed in relation to the legal and fiscal treatment of organisations rather than the nature of the economic activity being performed. However, there are important debates about institution-design in the UK (see Grout and Yong, 2003).
} 
Our approach is stylised, and the main goal is to offer a different theoretical perspective on both incentives and competition as applied to public service provision and thereby inform the policy debate. Our framework allows us to understand how productivity in public services can be increased by competition, without appealing to a standard model of market discipline. ${ }^{5}$ We do not aim to provide a balanced account of various aspects of the policy debate about public service reform. Moreover, while we do refer to specific public services like education and health to illustrate our framework, each of these cases raises many important case-specific issues; a comprehensive treatment of which is beyond the scope of the paper.

The plan of the paper is as follows. In the next section we discuss the key organisational issues involved in the provision of public services, emphasising how competition and mission-orientation affects incentives. In Section 3, we compare the three canonical models of public service provision, and evaluate them in the light of our framework. In Section 4, we draw some specific organisational lessons concerning public service reform based on our analysis. In Section 5, we address two additional issues; the potential costs of allowing greater choice and competition if (some) consumers are poorly informed and, in terms of increasing inequalities in access to public services, the factors governing optimal ownership of public goods.

\section{The Approach}

In this section we discuss the key organisational issues involved in the provision of public services, discussing both those that have been discussed in the existing literature, and those that we emphasise. It is convenient to separate two different organisational dimensions:

- Vertical dimension: This is the classic principal-agent problem. The main concern is that providers put in less effort than consumers would wish (shirking) or else may find ways of diverting resources to their own ends (rent extraction). The reform problem is to reduce both of these problems.

- Horizontal dimension: This concerns the mix of services and the priorities attached. The issue here is making the service mix correspond more closely to what the consumers desire.

In this section we will focus mainly on the vertical dimension. The two dimensions are, of course, interrelated. For example, the product-mix will govern the incentive problems - a move towards "quality" away from "quantity" will reduce the effectiveness of using high-powered incentive contracts as quality is harder to measure. Also, empowering consumers means that the nature of the principal-agent problem changes. The hierarchical or centralised model of public service provision is illustrated in Figure 1.

\footnotetext{
${ }^{5}$ LeGrand (1991) calls such markets "quasi-markets".
} 


\section{Figure 1}

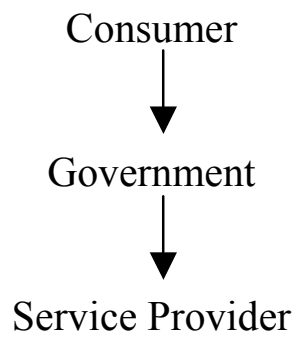

Consumers delegate elected officials to provide public services on their behalf by dealing with service providers. This model has two layers of agency problems: between the consumer and elected officials (which are mediated through elections or referenda) and between the government and the service provider. Empowering consumers means the structure of the problem is now:

\section{Figure 2}

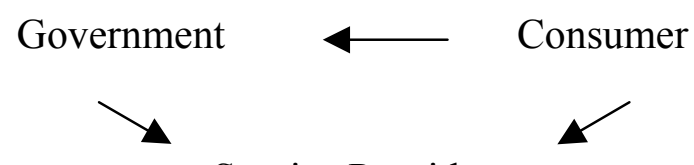

Service Provider

This provides a closer link between consumers and service providers. In Section 5 we will explore further the inter-connections between the vertical and the horizontal dimensions.

Any organisation is a network of principal-agent relationships. The accountability structure defines the rules of the game, ie, the chain of command and control, and the formal authority that each principal and agent is governed by. As in all such relationships there are informational asymmetries and monitoring problems, and inducing agents to act according to the objectives and coordinating the activities of these various actors, are the key issues of organisation design. To illustrate what is special about public organisations let us think in terms of the following two examples:

Example 1 A School: The principals are the head-teacher, local education department officials/politicians and the parents. The agents are the classroom teachers.

Example 2 A Hospital: The principals are the hospital administrators, Department of Health officials/politicians and the patients. The agents are the doctors and patients.

In the standard principal-agent model, there is a single principal to whom the agent is accountable. For example, in a for-profit firm every agent, from the delivery boy to the divisional manager are all, in the ultimate analysis, accountable to the owner(s) of the firm. While many people can be affected by the actions of the agent, in the absence of externalities, these can all be reduced to profits to the principal. ${ }^{6}$ The

\footnotetext{
${ }^{6}$ If externalities are present, eg, the firm's output creates pollution as a by-product then, of course, this conclusion needs to be modified.
} 
existing literature (see Dixit, 1996, 2002 and Burgess and Metcalfe, 1999) has focussed mainly on three respects in which public services differ. These are, the presence of multiple principals, the difficulty of measuring performance, and the importance of multi-tasking considerations. We briefly discuss each of these.

- Measurability: In many cases the services in question are complex and, as a result, the objectives of the relevant organisations are somewhat imprecise. For example, the objective of a school is to provide "good education", but this is much harder to define compared to say, production of rice or provision of banking services, or even some public services such as garbage removal or power supply. This means that in these cases it would be hard to find good performance measures. If performance measures are noisy, then making rewards very sensitive to performance does not give effective incentives and imposes unnecessary risk on the employee.

- Multi-tasking: One reason why these services are complex is because they involve several dimensions. For example, good education involves students being able to achieve high scores in standardised tests, but also encouraging a spirit of creativity, curiosity and inculcation of good values. The former is easy to measure but if teachers are rewarded just on the basis of the performance of students in tests, this might lead to an excessive focus on test-taking skills at the expense of the other components of a good education. This makes provision of incentives hard when employees have to perform multiple tasks (Holmström and Milgrom, 1991). Similarly, if hospitals are given incentives to cut costs, they are going to sacrifice quality by refusing to treat certain types of illnesses or being excessively selective in using expensive medical procedures. If the employee has to do several tasks, and some of these have good performance measures and others not, then making her/his pay sensitive to the good performance measures will cause her/him to substitute effort away from the other tasks, and could result in a loss of efficiency.

- $\quad$ Multiple Principals: As the above examples suggest, public services typically involve multiple principals. This has been widely recognised in the literature on incentives (see, for example, Dixit, 2002). There are several reasons for this. First, by their very nature they generate direct consumption and production externalities. For example, how education and health services are provided is a matter of concern for society as a whole, and not just those who receive the services. Better education makes better citizens. Similarly, a healthier population is less likely to spread infectious diseases. So society at large can be thought of as an additional principal. Second, due to the presence of these direct externalities, these services have to be provided through second-best arrangements which then generate indirect externalities, and consequently, another layer of multiple principals. There are several actors who are directly affected by the actions of an agent in the provision of public services. For example, a doctor can be concerned with the success of a particular treatment method. This can be in conflict with the interests of the hospital management (or taxpayers at large) who would like to minimise costs. This can also be in conflict with patients, who might not wish to be subjects of experimentation. Similarly, a teacher might want to give more emphasis on learning using expensive teaching aids, as opposed to imparting mechanical test-taking skills. 
This might make the (enlightened) parents happy, but the school principal or management might care more about the average test-record of their students, whilst taxpayers may be more concerned about the expenses. ${ }^{7}$ Since each principal would like to induce the agent to put more effort in activities that $\mathrm{s} / \mathrm{he}$ cares about more, if the incentive schemes are not chosen to maximise the joint payoffs of the principals due to the externalities, there will be inefficiencies over and above the basic agency costs. Typically, the distortions are in the direction of making the incentives facing the agent less high-powered. If these tasks are complements (or there is a single task which all the principals care about) then there is a basic free-riding problem which will lead to lower incentive payments to the agent. If these tasks are substitutes, then each principal would like to pay the agent to do more of the task $\mathrm{s} /$ he likes and less of the task that $\mathrm{s} / \mathrm{he}$ does not like. This means each principal dilutes the incentives offered by other principals, making the agents' incentives less high-powered.

Without wishing to de-emphasise the importance of these considerations, we would like to focus on the following three components in the design of an organisation for providing a public service: mission design, matching and motivation.

\subsection{Missions}

Public service provision often takes place in mission-orientated firms. The mission of the organisation displaces the conventional notion of profit maximisation used in the case of private sector organisations. The idea that missions are important in public organisations is not a new idea. It is a central plank of James Q. Wilson's celebrated study of public bureaucracies (Wilson, 1989). He defines a mission as a culture "that is widely shared and warmly endorsed by operators and managers alike." (Wilson, 1989: 95). The notion that the missions of organisations are also important is a frequent theme in the literature on non-profit organisation (see, for example, Sheehan, 1998). It is the nature of the activities in question and not whether the service is provided public or privately that unites mission-orientated organisations.

While the notion of mission is somewhat vague compared to more tangible notions like profit, we believe that it is an important departure when thinking about how organisations that are not directly responsive to market forces behave. ${ }^{8}$ In so far as principal and agents share a view of the mission, it is likely that an effective mission will economise on monetary incentives.

We assume that the mission of the organisation is determined by the principals in the organisation. This can be a heterogeneous group with overlapping responsibilities.

\footnotetext{
7 The presence of multi-tasking considerations clearly compound these problems. As opposed to some general notion of effort, teachers and doctors perform different (and complex) tasks. These different principals might have very different preferences over the outcomes of these tasks. For example, consider how much emphasis the teacher puts on topics which are controversial (in some parts of the world), such as evolution. This is similar to the problem that arises if a doctor is keen to push some particular line of treatment we mentioned earlier.

${ }^{8}$ Missions can also be important in more standard private sector occupations. Firms frequently profess that their goal is to serve customers rather than to make their shareholders as rich as possible. However, it is unclear whether these are genuine missions, or just a veil for some other underlying self-interested behaviour.
} 
For example, in the case of a school, they are the parents, the government and the headteacher. Preferences over missions can be heterogeneous. For example, some parents may value high levels of discipline. There could also be disagreement on the right curriculum choices, such as the weight to be attached to music teaching or languages. An important role of the management in a mission-orientated organisation is to foster a congruent outlook. Thus, as Miller (2002) argues in the context of her case studies of twelve non-profit organisations, "Non-profit boardmembers do not expect conflict between the executive director and the purpose for which the organisation was created. The board believes that the executive management will not act opportunistically and that what management actually does is ensure good alignment and convergence in its relationship with principals." (Miller, 2002: 446-7).

Changing the mission of an organisation in a way that is not favoured by the agents can reduce the efficiency of the organisation. In that sense, the approach shows why mission-orientated organisations are conservative and slow-moving since there is a rigidity built in from the types of agents who are attracted to the organisations. Organisations without mission-orientated agents, such as private firms, are likely to be more flexible and adaptable.

\subsection{Motivation}

A key assumption is that the provision of public services benefits from the effort put in by these agents and that high quality public services require a high intensity of effort. It also depends on the abilities of the service providers and the quality of the capital inputs that they use. We assume that this effort is costly and that the agents in question have to be motivated to put in effort. But rewards for putting in effort are not purely pecuniary - agents could be motivated to provide high quality services because they care about the output being produced. However, the non-pecuniary rewards depend on the way in which the organisation is structured. For example, teachers may care about teaching to a curriculum that they think is most conducive to learning. Thus, the mission of the organisation can affect the degree to which agents are willing to commit costly effort.

When goods are produced with external benefits, then individuals who work in the production of these goods may factor the value of the output that they produce in their decision to work in that sector and into the amount of effort that they put in. This is the labour market equivalent of the idea that individuals engage in private supply of public goods and those with the highest valuation of public goods may have the greatest interest in contributing. The model could also be one in which individuals are "altruistically" motivated or that they get a "warm glow" from doing social good. 9 In the former case, the level of the good being produced matters to the individual, but not who provides it. This can lead to free-riding. In the latter case, it is not the level of the good, but how much the individual himself/herself contributes to it that matters. It is clear that with either of these views the value of what they do should be attached to the job that they do, and not the sector in which they do it. Thus, if a nurse believes that nursing is an important social service with external benefits, then it should not matter whether s/he is employed by the public or private sector except in so far as this affects the amount of the benefit that s/he can generate.

\footnotetext{
9 These ideas are also related to the strong professional ethics that govern the behaviour of workers in the production of collective goods. Such ethical codes de-emphasise narrow self-interest.
} 
The general point here is that a system of organisation and remuneration for the provision of public goods will have to take into account not only the effect of on-thejob incentives on how those in the sector work, but also who is attracted to work there. This might alleviate the need to give high-powered incentives. Francois (2000) has shown the fact that government bureaucrats are not residual claimants, implying that they can commit to a "hands-off" policy which elicits greater effort from workers who have "public service motivation". However, if individuals differ in terms of how motivated they are, and in addition have heterogeneous mission-preferences, it is important to examine the process by which agents are matched to an organisation, a topic which we turn to now.

\subsection{Matching}

Matching is the process by which principals and agents come together to create an organisation. This could be governed by choice, as when a parent picks a school for their child, or by government policy. Matching serves an allocative role in bringing consumers to providers ("product market matching") and of workers to providers ("labour market matching").

If consumers care about the missions adopted in public organisations, then allowing them to choose between public service providers with different missions is a potentially important source of welfare improvements. There is no reason why a consumer could not exercise choice between two competing hospitals or schools in much the same way that they choose a TV or a car. It is true that it may be more costly to acquire information about healthcare services. Also relationship-specific investments may be important for health and education, making switching more costly. But these are differences in degree, not in kind. Moreover, complex choices such as provision for old age are routinely left to private decision-making. This application of private good choice to public services underpins the standard argument for voucher provision of public services. The state provides the citizens with a voucher that entitles the individual to a particular service (or it could be a monetary amount) and they then choose where to spend that voucher. This is, effectively, the kind of system in place for eye tests for low income individuals in the UK.

Principals and agents can match with one another on the basis of the perceived mission of the organisation. This is a natural consequence of organisations being mission-orientated. This matching increases efficiency in the operation of public service organisations since the returns from putting in effort are higher when agents share the same goals as those espoused by the organisation.

\section{Three Models of Public Service Provision}

In this section, we discuss three very stylised models of public service provision. The first is pure market provision - the model on which much of the discussion of public service reform gets discussed. As outlined below, it has three distinctive features.

- $\quad$ Model 1: Market Provision

- Missions and consideration of agent motivation are irrelevant. 
- Competition works through either intensification of the returns to effort or through greater use of yardstick comparisons.

- Monetary incentives matter above all - if measurement of the agent's performance is good, then these will tend to be high-powered.

The fact that the standard market model uses monetary incentives is part and parcel of the fact that it does not take advantage of agent motivation. It emphasises the joys of competition in reducing slack and through the effect on the process of profit generation and yardstick competition. Both of these are championed by many parties in the public service reform debate.

- Model 2: Traditional State Provision

- $\quad$ Single centralised mission for all providers.

- Limited use of monetary incentives.

- No competition.

This is the much derided model from which public services are moving. Key features are the lack of competition and incentives. Moreover, the mission of the public sector providers is determined centrally with little regard to the interests of providers and customers.

- Model 3: Decentralised Provision

- Heterogeneous missions.

- Competition by matching of providers, workers and customers.

- $\quad$ Limited use of monetary incentives.

We believe that Model 3 is the right model for an efficient system of public service delivery in many contexts. It differs from Model 2 in emphasising decentralisation and choice. The role of competition to provide effective matching in the preferences of principals and agents. It differs from Model 1 in de-emphasising monetary incentives. It is the process of effective matching that allows organisations to economise on the use of explicit incentives. It also gives weight to finding effective means to allow organisations to develop missions.

\section{$4 \quad$ Lessons}

In this section we would like to draw some specific organisational lessons concerning public service reform based on our analysis.

- $\quad$ Lesson 1: The importance of choice and competition.

In our approach, competition matches principals and agents. This increases organisational efficiency by economising on the need for explicit incentives. This 
mechanism is quite different from those that have typically been studied in either the literature on competition and incentives in public services, or that on competition in principal-agent relationships.

The importance of competition was at the heart of the "quasi-market" reforms that were pushed in the UK in the early 1990s. However, the model of competition that underpins this was never really spelt out. Commentators on these, such as Glennerster (1991) and LeGrand (1991), were sceptical about the link between these internal markets and the strive for efficiency. However, it is clear that they were thinking about a model based on the role of competition in sharpening the firms' incentives by reducing managerial slack via fear of losing pupils or patients. But, given that residual claimants in public services are so ill-defined, it is less clear than in a private firm how strongly public service providers will have an incentive to resist organisation contraction. Perhaps, if, as suggested by Niskanen (1971), bureaucrats are budget maximisers, then this has some hope of success. But outside of this kind of simplistic public choice objective, things look less promising.

The theoretical link between competition and effort incentives in principal-agent relationships is also weak in those situations most applicable to public services. There are two main models. First, competition can affect the principal's payoff and the way in which it depends upon the effort of agents. Thus, stronger product market competition could affect the marginal sensitivity of output to agent effort. The issue is whether more intense competition leads to agents having to work harder to generate a successful return for the principal, thereby encouraging effort. Second, competition can effect the information available to the principal through performance comparisons (so-called yardstick competition). Thus, IBM could choose to reward its managers according to the performance of Hewlett-Packard as a means of encouraging greater effort. This makes sense when the two firms are subject to similar (unobserved) shocks (see Holmström, 1999).

A large literature, reviewed in Nickell (1996), has looked at these arguments. Neither argument yields strong and robust links between intensity of competition and managerial effort. Arguments based on the way competition affects the marginal return to managerial effort are quite sensitive to the exact specification of the model. Moreover, even though competition can intensify the link between profits and effort, it may do so by increasing the extent of the risk to which the manager is exposed (see Raith, 2002). This may undermine the intensification effect to some degree. Also, since product rents affect the extent to which principals wish to incentivise agents, greater competition can reduce a firm's desire to offer high-powered incentives (see Schmidt, 1997). As Schmidt (1997) shows, the only robust argument that links competition and effort is via the way that competition increases the probability that a firm will be liquidated.

The argument for unambiguous advantages from yardstick competition is sensitive to the kinds of contracts that agents can be offered. The case is strong when the principal can offer complete incentives to agents as in Holmström (1999). However, environments with greater contracting frictions, such as implicit incentive models based on reputation, yield more ambiguous results. Dewatripont, Jewitt and Tirole (1999) emphasise how greater information on the performance of agents need not be welfare-enhancing in such situations. However, this has not stopped the use of league 
tables and other performance comparisons, quite popular in the UK, which are clearly geared towards greater use of yardstick comparisons.

- $\quad$ Lesson 2: The case for high-powered monetary incentives in public services is weak.

The fact that agents may be motivated may reinforce the tendency towards lowpowered incentives which has been discussed in the literature. If the employee receives a non-monetary reward from doing her/his job well, then clearly s/he can be paid both a lower wage and her/his pay does not have to be made very sensitive to her/his performance.

The approach developed here makes clear how the often-made claim that mission alignment is a substitute for monetary incentives works. We would expect organisations with better matching of mission preferences to rely less on explicit monetary incentives. Monetary incentives are most important when principals and agents disagree about the mission. Mission-orientated organisations should use highpowered monetary incentives only if matching is poor. Cross-sectionally, the approach therefore predicts that higher use of monetary incentives is likely to be negatively correlated with effort levels (productivity). This is a striking implication of our framework, as it turns on its head the conventional view about the superiority of the private sector because it uses incentive schemes. The so-called New Public Administration (see Barzelay, 2001) emphasises the need to incentivise public bureaucracies and to empower consumers of public services. Relatedly, Osborne and Gaebler (1993) describe a new vision of public administration, emphasising the scope for dynamism and entrepreneurship in the public sector. Our approach casts light on the intellectual underpinning for these approaches. Greater use of incentives in the public sector is a symptom of poor alignment of missions. It seems unsurprising that these ideas were born in periods of great bureaucratic stress - in New Zealand and the UK in the 1980s, when both of which were being run by governments (principals) who did not share the traditional bureaucratic values.

- $\quad$ Lesson 3: Accountability and incentives are linked.

Think of a proposal to empower parents within a school or patients within a hospital. Then, if successful, this will increase the weight in the decision-making process attached to their preferences. This may increase or decrease mission alignment in public organisations. If it decreases it, then other forms of motivation (such as monetary incentives) need to be considered. If congruence in mission alignment is increased as a result of accountability changes, then the need for incentives is weakened.

Attempts to reform mission-orientated organisations by changing accountability will often change the quality of existing matches. This explains why mission-orientated organisations are inherently conservative and attests the difficulties in reforming public sector organisations. It may also explain the preference for bringing in outsiders - so-called political appointees - to change the organisational culture.

- Lesson 4: Public organisations are less responsive to external shocks due to their mission-orientation. 
Our approach casts some light on responses to change in public organisations that are mission-orientated. Because mission preferences are locked-in by matching, attempts to reorganise modes of working (one form of which is changes in the structure of accountability discussed above) will lead to reductions in organisational productivity. This is often portrayed as a decline in morale in organisations that are undergoing major transformation. Organisations without selection on mission will not face this demoralising effect. This provides a possible underpinning for the difficulty in reorganising public bureaucracies. Over time, as the matching process adjusts to the new mission, this effect can be undone so we might expect the short- and long-run responses to change to be rather different. Empowerment of beneficiaries in public programs is also an important issue. It is frequently suggested that public organisations work better when members of their client group get representation and can help to shape the mission of the organisation. Thus, some advocate that parents should be given a greater say in school governance. This works fine provided that teachers and parents share similar educational goals. Otherwise, attempts by parents to intervene will simply increase the degree of non-alignment of preferences, and reduce the efficiency of schools. Again, we might expect significant differences between short- and long-run responses when matching is endogenous.

\section{$5 \quad$ Other Issues}

\subsection{Costs of Choice and Competition}

We have focused here on the potential benefits from allowing for a more heterogeneous and diverse set of public services shaped by competing missions. But there are potential costs too. Here we discuss two of these - the possibility that consumers are poorly informed and that inequalities in access to public services will be exacerbated.

\subsubsection{Information}

There are a number of concerns about the extent to which choice can be trusted in public service provision. Choice in the provision of private goods works best when consumers are well-informed. The market may fail to achieve an efficient outcome for goods which are purchased infrequently or whose usefulness becomes apparent only after a prolonged period of use. In such cases, poor quality firms survive for long periods. Without appropriate legal protection it may also be difficult for consumers to call poor performing firms to account for supplying low quality or faulty products. There is a well established body of regulations which underpins the functioning of markets and which tries to prevent such problems. The market may also provide its own response in the form of information providers, such as the Consumers' Association, and professional associations, such as the Law Society.

Choice also creates a premium for informed consumers - those who know about the quality or public services or are willing to invest in information. The system of public service provision that has dominated in the UK for more than 50 years has not been one in which beneficiaries have significant gains from being informed. This suggests the need to focus on information provision for consumers as part of any reform strategy where choice is enhanced. 
However, this is not easy. The parallel with private pension provision is telling. Leaving individuals to exercise private choices on such important lifetime decisions must be put alongside the evidence on the huge extent of continuing consumer ignorance on pension issues. Restricting choice may be paternalistic, however, it may save certain groups from making the wrong decisions. This raises philosophical issues that go beyond the economic aspects of the problem that this paper focuses on.

\subsubsection{Inequality}

A further source of concern is the fact that choice and competition are frequently associated with stratified public services where higher income and better informed individuals get access to better public services. While so far we have focused on mission as the basis for supplier and customer matching, matching could arise on the basis of the degree of motivation of the principals and agents. Thus, the most committed teachers may end up working in schools where the parents value education the most. ${ }^{10}$ This will lead to schools that are stratified in terms of quality.

Inequality can also arise as a consequence of the production technology for the provision of public goods - the fact that service quality can depend on how many and what kinds of customers choose to use the service. The best analogy for such cases is thinking of joining a club where you care about with whom you will associate and whether the club facilities will be crowded or not. The classic example of this in education arises if there are peer group effects - whereby the amount of learning that a child does is affected by the behaviour and ability of other children in the class. Choice is now more complex since an individual must anticipate who else will choose to consume a public service at the point at which they make their consumption choice.

Tiebout (1957) laid out an economic framework for thinking about choice and competitive provision in this context. He envisaged (local) public goods being provided by a variety of providers located in jurisdictions with consumers choosing to live in the jurisdiction that came closest to representing their preferences. In a fully decentralised system, this would involve choosing both a tax and service provision level. Some consumers who did not value public services at all could, in principle, opt out altogether, while others could opt to pay more tax and receive more services. In Tiebout's world, it is local taxes that "clear the market". In the UK, there is evidence that house prices may play some role in doing this in the case of schools (see Gibbons and Machin, 2002).

One key feature of the Tiebout world is that public goods provision is stratified. This stratification could be by income or quality of service. There is clearly a tension between pursuing goals of equality in service provision and greater decentralisation and choice when the production process depends on who else is consuming the goods (see Epple and Romano, 2002). This dilemma is put well in LeGrand (1991) as follows: "In education, selective schools may arise that cream off the most able pupils leaving 'sink' schools for the remainder. Healthcare providers, such as GPs with practice budgets, or self-governing hospitals, will compete for the custom of the young and comparatively healthy, while ignoring the elderly or chronically sick. In social care, residential homes will compete for healthy elderly people, while ignoring

\footnotetext{
${ }^{10}$ Of course, this possibility is undermined if teachers care directly about inequality in educational provision.
} 
those who are senile and incontinent. Since there is likely to be a greater concentration of the 'bad risks' among the poor and deprived, the latter may end up receiving fewer services relative to those received by the better-off, thus widening inequality." (LeGrand, 1991: 1266).

This is a real trade-off and indeed, if these costs in terms of inequality are significant then they could wipe out the potential efficiency gains from decentralisation. However, the centralised model of the welfare state, too, has costs in terms of efficiency, and indeed some in terms of inequality (LeGrand, 1991). Unfortunately, the evidence is scarce and inconclusive. ${ }^{11}$

There are some hybrid models that do not fit either of the pure versions of the centralised and the competitive models. In principle, externalities that cause inequalities could be dealt with by appropriate adjustments in funding formulae which "price" the externalities in question. One specific idea along these lines has been suggested in the literature on school vouchers which is often rejected on grounds of inequity (see Ladd, 2002). This is to adjust the voucher amounts to characteristics of students (eg, students who come from a poor background or belong to minority groups, or those who are disabled would receive larger vouchers) and to the characteristics of the schools (eg, schools that are economically or otherwise more integrated would receive larger vouchers). Obviously this scheme might be difficult to implement. If that is the case, one should try to find other, more implementable, measures that address the inequality issue in a world with greater choice in public services before concluding that the "one-size-fits-all" solution is the only feasible one.

Also, while the problem of increasing inequality with greater choice is a legitimate concern, it is not inevitable. Many of proponents of school competition in the US have argued that it is a "tide that lifts all boats" (Hoxby, 2001). Proponents of Foundation Hospitals make similar claims. The key issue is whether competition and decentralisation can increase productivity in some places without reducing it in others. Increases in inequality from such improvements are harder to argue against than those that increase productivity in some places at the expense of others.

\subsection{The Role of Ownership}

The current policy agenda is putting more weight on solutions involving continued public finance with less reliance on public provision. The trend towards contracting out, which began long ago, is one version of this. The current debates are even more far-reaching. For example, should we go beyond even contracting out and just use vouchers and rely on market provision? This raises fundamental questions about the boundaries of the public sector. What is the role of ownership in the context of public goods and services? How is resource allocation affected if the government decides to provide a service in-house, or contracts out provision to a for-profit or a non-profit firm? As emphasised in the introduction, ownership is an aspect of organisation design, the goal of which is to provide the best possible incentives to the various actors.

It is now well understood that situations where ownership matters for incentives are ones where contracts are incomplete and subject to renegotiation. According to the

\footnotetext{
${ }^{11}$ See Ladd (2002) and Hoxby (2003) for a review of the evidence in the context of education.
} 
property rights approach pioneered by Oliver Hart, Sanford Grossman and John Moore (see Hart, 1995), the allocation of ownership affects incentives to undertake non-contractible, relationship-specific investments in a project. Because these investments are not contractible, there is some ex post bargaining over the surplus that is generated by these investments. As ownership positively affects bargaining power you can always threaten to fire the other parties if it improves the investment incentive of the owner, but reduces that of non-owners. The optimal ownership structure is one that is associated with the highest surplus. Besley and Ghatak (2001) develop a theory of ownership in public goods provision which is relevant to the study of public service provision.

Consider a simple example. Suppose there are two parties, $A$ and $B . B$ can undertake two possible levels of investment, high and low, and the costs of these two types of investment are 2 and 0 . $A$ does not undertake any investment. When $B$ undertakes the low investment, total profits are 10, but with the high investment total profits are 15 . From the social point of view, clearly the high investment should be undertaken by $B$ since the marginal gain, 5, exceeds the marginal cost, 2. Assume if $B$ walks out of the project after the investments are undertaken, $A$ can realise only $80 \%$ of the potential profits because part of the investment is embodied in the human capital of $B$. However if $A$ walks out, $B$ can realise the full return of the project. Assume further that the party that walks out (or is fired) has an outside option of 0 .

If the investment choices of $B$ are contractible, or the profit levels are contractible, then $B$ should be paid a fee of 2 or more, conditional on the high investment being undertaken, or conditional on profits being high and that should result in the efficient outcome irrespective of ownership. But suppose due to transactions costs, neither $B$ 's investments, nor the profit levels are contractible. $B$ will not have an incentive to undertake the investment if $A$ makes an up-front payment because of its noncontractibility. Similarly, $A$ will not have an incentive to make a transfer to $B$ if profits are high. Rather, the parties are likely to bargain over the surplus after the investment is sunk, and the choice of investment would depend on the share of the surplus received by the investing party.

If $A$ is the owner, s/he can threaten to fire $B$. If the high investment is chosen, the outside options are $15^{*}(0.8)=12$ for $A$, and 0 for $B$. Using the Nash bargaining solution, in this case, $B$ receives a profit of $(15-12) / 2=1.5$, and $A$ a profit of $(15+$ $12) / 2=13.5$. $B$ 's profits are less than the cost of investment, 2 . Therefore anticipating this hold-up problem, $B$ would not invest if $A$ is the owner. In contrast if $B$ is the owner, s/he can threaten to fire $A$. Now $B$ receives a profit of $(15+15) / 2=$ 15 and $A$ a profit of $(15-15) / 2=0$. $B$ 's profits are higher than the cost of investment and so $\mathrm{s} / \mathrm{he}$ invests.

The above example shows that as $B$ 's investment could be more important for the project than $A$ 's, $B$ should optimally be made the owner. If $A$ too could undertake some investment, and if both $A$ 's and $B$ 's investment decisions were sensitive to incentives, ownership would depend on the relative importance of the investments of the parties involved. This is one of the key insights of the Grossman-Hart-Moore framework. In the simple example above, where there is a single investor, it obviously follows that this investor should own the asset. Ownership by any other party would only undermine her/his incentives, without brining in any gains. 
Besley and Ghatak (2001) show that this conclusion is significantly affected if we consider public goods and services. They show that it may be optimal to transfer ownership of a public project to private sector organisations such as non-profits on the grounds that they care relatively more about the benefits generated by such projects. This result holds regardless of whether such organisations are also the key investors. This result reflects a key property of public goods - during the renegotiation of the project for a public good, each party values the project whether or not they are actually involved in it. Contractual incompleteness implies that ownership of a public project should reside with the party that cares most about the project being successful. This gives the best investment incentives to that party, as well as to others. This highlights the fact that, when public goods are being considered, the motivation of providers is important and not just the technological factors as typically highlighted in the context of private goods.

Let us modify the above example to illustrate this case. Suppose the outcome of the project is an improvement in the quality of a school. $A$ gets a payoff of 14 when $B$ undertakes the high investment, and a payoff of 10 when $B$ undertakes the low investment. $B$ 's payoffs are 1 and 0 respectively, so that the total benefits are the same as in the case where the project involved a private good. Everything else is as before. If $A$ is the owner then in the event of disagreement $B$ now gets a payoff of $1 *(0.8)=0.8$ (since this is a public good, otherwise s/he would get 0 ), and $A$ gets a payoff of $14^{*}(0.8)=11.2$ and so $B$ 's equilibrium payoff is $(15-11.2+0.8) / 2=2.3$ $>2$. So $B$ invests. But $B$ is the owner so in the event of disagreement, $B$ gets a payoff of 1 and $A$ gets a payoff of 14 (once again, because this is a public good) and so $B$ 's equilibrium payoff is $(15-14+1) / 2=1<2$. In this case, $B$ therefore does not invest.

Hence, ownership by $A$ yields the joint surplus maximising level of investment in this example. Thus, it may be optimal for the party that does not have a comparative advantage in any task or important specific investments to undertake, to own the project. Ownership acts as a commitment device to reward investments in the public project. This undercuts the efficiency argument that is often made against government ownership. If the government has a higher valuation for a public good, it should be the owner since that allows it to credibly commit to finance it. At the same time, it gives a reason why a non-profit organisation might be involved as an owner, if they happen to have a higher valuation.

\section{Concluding Comments}

When it comes to public service reform, what matters for effective delivery of public goods and services are accountability structures and incentives. Ownership issues are given far too much weight in existing debates about public service reforms. We have argued that the mission of organisations is important in motivating agents in public services. It is important to think about how the mission of the organisation, and hence the motivation of the agents, are affected by proposals to reform public services. The main potential for competition in public services lies in achieving matching providers and employees in the labour market and in matching customers to providers. Better matching reduces the need for giving incentives and can enhance productivity. This logic underpins the move towards greater decentralisation and choice in public service provision. 
Each public service comes with its own set of issues and problems. While we feel that Model 3 from Section 3 above has general merits as a model of public services, it is likely to be most relevant when three things are true - (i) there are a variety of legitimate missions which customers and producers care about, (ii) unmonitored effort is an important component of production and (iii) consumers are sufficiently wellinformed (or can be made so) about the options available. In relatively monolithic public services, the argument for choice and variety is weak. The model seems very compelling in the case of education and in some kinds of healthcare provision. It does not seem particularly relevant in postal services, processing tax returns or issuing passports. The latter are cases where the "private sector" model seems more compelling. Traditional arguments for the use of yardstick competition may also have an important role to play.

The notion that competition in public services and greater decentralisation can be valuable is far from new. ${ }^{12}$ However, the literature has lacked a framework that ties together competition, incentives and accountability when the objectives of the organisations are not profit-maximisation. We have stressed here that the value of competition need not work via a public service provider's revenue function (ie, whether your sales drop as you have more rivals), as it does in the conventional "industrial organisation" model of competition. Instead competition leads to better alignment on mission preferences. This attenuates incentive problems and allows the organisation to better serve the interests of consumers as well as attaining higher levels of productive efficiency.

But there are legitimate concerns. Public service reform of the kind that we have described puts a premium on mobility and information which is likely to favour the rich. The approach that we outline emphasises that gains for some do not necessarily come at the expense of losses to others. Indeed, it is possible (theoretically) that the quality of all public services improves. Clearly, this is the rosy scenario on which many current policy initiatives are premised. The reality will become clear in due course. At the same time, it is clear that the centralised model, with little diversity and a lot of administrative costs, is now on the back foot. Our approach discusses the drawbacks theoretically. However, theory (at best) can only help us understand the big picture a bit better in the light of available evidence. In the path ahead of us the challenge lies in the details.

\footnotetext{
${ }^{12}$ See, for example, Glennerster (1991), LeGrand (1991) and LeGrand and Bartlett (1993).
} 


\section{References}

Atkinson, A B and Stiglitz, J E (1980) Lectures on Public Economics. New York: McGraw Hill.

Barzelay, M (2001) The New Public Management - Improving Research and Policy Dialogue. Berkeley \& Los Angeles: University of California Press.

Billis, D and Glennerster, H (1998) "Human Services and the Voluntary Sector: Towards a Theory of Comparative Advantage," Journal of Social Policy, 27 (1): 7998.

Burgess, S and Metcalfe, P (1999) "Incentives in Organisations: A Selective Overview of the Literature with Application to the Public Sector," Working Paper No. 99/016, The Leverhulme Centre for Market and Public Organisation, University of Bristol.

Besley, T and Ghatak, M (2003) "Competition and Incentives with Motivated Agents," typescript, LSE.

Besley, T and Ghatak, M (2001) "Government Versus Private Ownership of Public Goods," Quarterly Journal of Economics, 116 (4): 1343-1372.

Dewatripont, M, Jewitt, I and Tirole, J (1999) "The Economics of Career Concerns," Review of Economic Studies, 66 (1): 189-217.

Dixit, A (2002) "Incentives and Organisations in the Public Sector: An Interpretive Review," Journal of Human Resources, 37 (4): 696-727.

Dixit, A (1996) The Making of Economic Policy - A Transactions-Cost Politics Perspective. Cambridge, MA: MIT Press.

Epple, D and Romano, R (2002) "Educational Vouchers and Cream-Skimming," NBER Working Paper \#9354.

Francois, P (2000) "Public Service Motivation as an Argument for Government Provision," Journal of Public Economics, 78 (3): 275-299.

Gibbons, S and Machin, S (2001) "Valuing Primary Schools," DP 15, Centre for Economics of Education, LSE.

Glennerster, H (1991) “Quasi-Markets for Education,” Economic Journal, 101: 12681276.

Grout, P and Yong, M (undated) "The Role of Donated Labour and Not for Profit at the Public/Private Interface," typescript, University of Bristol.

Hart, O (1995) Firms, Contracts and Financial Structure. Oxford: Oxford University Press. 
Holmström, B (1999) "Managerial Incentive Problems: A Dynamic Perspective," Review of Economic Studies, 66 (1): 169-182.

Holmström, B and Milgrom, P (1991) "Multi-task Principal-Agent Analysis: Incentive Contracts, Asset Ownership, and Job Design," Journal of Law, Economics and Organisation, 7 (Special Issue): 24-52.

Hoxby, C M (2003) "School Choice and School Competition: Evidence from the United States," typescript, Harvard University.

Hoxby, C M (2001) "School Choice and School Productivity (or Could School Choice be a Tide that Lifts all Boats?" typescript, Harvard University.

Ladd, H F (2002) "School Vouchers: A Critical View," Journal of Economic Perspectives, 16 (4), 3-24.

LeGrand, J (1991) “Quasi-Markets and Social Policy,” Economic Journal, 101: 12561267.

LeGrand, J and Bartlett, W (1993) Quasi-Markets and Social Policy. London: MacMillan.

Miller, J L (2002) "The Board as Monitor of Organisational Activity: The Applicability of Agency Theory to Non-profit Boards," Nonprofit Management and Leadership, 12 (4): 429-450.

Nickell, S (1996) "Competition and Corporate Performance," Journal of Political Economy, 104 (4): 724-746.

Nickell, S (1995) The Performance of Companies. Oxford: Basil Blackwell.

Niskanen, W (1971) Bureaucracy and Representative Government. New York: Aldine-Atherton.

Osborne, D and Gaebler, T (1993) Reinventing Government: How the Entrepreneurial Spirit Is Transforming the Public Sector. New York: Plume.

Raith, M (2002) "Competition, Risk and Managerial Incentives," forthcoming in American Economic Review.

Schmidt, K M (1997) "Managerial Incentives and Product Market Competition," Review of Economic Studies, 64 (2): 191-213.

Sheehan, R (1996) "Mission Accomplishment as Philanthropic Effectiveness: Key Findings from the Excellence in Philanthropy Project," Non-profit and Voluntary Sector Quarterly, 25 (1): 110-123.

Tiebout, C (1956) "A Pure Theory of Local Expenditures," Journal of Political Economy, 64 (5): 416-424. 
Weisbrod, B A (1988) The Nonprofit Economy. Cambridge, MA: Harvard University Press.

Wilson, J Q (1989) Bureaucracy: What Government Agencies Do and Why They Do It. New York: Basic Books. 
- Precautionary Bans or Sacrificial Lambs? Participative Risk Regulation and the Reform of the UK Food Safety Regime

Henry Rothstein

DP 15

- $\quad$ The Invention of Operational Risk Michael Power DP 16
- $\quad$ Perceptions of Risk: an experimental approach using internet questionnaires Frank A. Cowell and Guillermo Cruces

DP 18

- $\quad$ Reforming the UK Flood Insurance Regime. The Breakdown of a Gentlemen's Agreement Michael Huber

DP 19

- Mapping the Contours of

Contemporary Financial Services

Regulation

Julia Black

DP 17

Available now in print or from http://www.lse.ac.uk/collections/CARR/documents/Default.htm

- Incentives, Choice and Accountability in the Provision of Public Services Timothy Besley and Maitreesh Ghatak

DP 14

- $\quad$ Regulating Parliament: the regulatory state within Westminster

Robert Kaye

DP 13

- Business History and Risk

Terry Gourvish

Business Risk and Antitrust:

comparative perspectives

Tony Freyer

The Risks of Working and the Risks of Not Working: historical perspectives on employers, workers, and occupational illness

Joseph Melling

DP 12

- The Open Method of Co-ordination and the European Welfare State Damian Chalmers and Martin Lodge

- Drivers and Drawbacks: regulation and environmental risk management systems

Marius Aalders

DP 10

- Conceptualising Insurance: risk management under conditions of solvency

Michael Huber

DP 9

- Social Licence and Environmental Protection: why businesses go beyond compliance

Neil Gunningham, Robert Kagan and

Dorothy Thorton

DP 8
- $\quad$ Neglected Risk Regulation: the institutional attenuation phenomenon Henry Rothstein

DP 7

- Mass Media and Political

Accountability

Tim Besley, Robin Burgess and Andrea

Pratt

DP 6

- Embedding Regulatory Autonomy: the reform of Jamaican

telecommunications regulation 1988-

2001

Lindsay Stirton and Martin Lodge DP 5

- Critical Reflections on Regulation Julia Black

DP 4

- The New Politics of Risk Regulation in Europe

David Vogel

DP 3

- The EU Commission and National

Governments as Partners: EC regulatory expansion in telecommunications 1979-2000

Mark Thatcher

DP 2

- $\quad$ Regulating Government in a 'Managerial' Age: towards a crossnational perspective

Christopher Hood and Colin Scott DP 1

- Is Regulation Right?

Robert Baldwin

Business Risk Management in

Government: pitfalls and possibilities Christopher Hood and Henry Rothstein

Risk Management and Business

Regulation

Bridget Hutter and Michael Power DP 0 